Marquette University

e-Publications@Marquette

$5-1999$

\title{
Thermal Degradation of Polystyrene, Poly(1,4-butadiene) and Copolymers of Styrene and 1,4-butadiene Irradiated Under Air or Argon with 60Co- $\mathbf{y}$-rays
}

\author{
W. Schnabel \\ Bereich Physikalische Chemie \\ Galina F. Levchik \\ Belorussian State University \\ Charles Wilkie \\ Marquette University, charles.wilkie@marquette.edu \\ David D. Jiang \\ Marquette University \\ Sergei V. Levchik \\ Belorussian State University
}

Follow this and additional works at: https://epublications.marquette.edu/chem_fac

Part of the Chemistry Commons

\section{Recommended Citation}

Schnabel, W.; Levchik, Galina F.; Wilkie, Charles; Jiang, David D.; and Levchik, Sergei V., "Thermal Degradation of Polystyrene, Poly(1,4-butadiene) and Copolymers of Styrene and 1,4-butadiene Irradiated Under Air or Argon with 60Co-y-rays" (1999). Chemistry Faculty Research and Publications. 749.

https://epublications.marquette.edu/chem_fac/749 


\section{Marquette University \\ e-Publications@Marquette}

\section{Chemistry Faculty Research and Publications/College of Arts and Sciences}

This paper is NOT THE PUBLISHED VERSION; but the author's final, peer-reviewed manuscript. The published version may be accessed by following the link in the citation below.

Polymer Degradation and Stability, Vol. 63, No. 3 (March, 1999): 365-375. DOl. This article is (C) Elsevier and permission has been granted for this version to appear in $\underline{\mathrm{e}}-$ Publications@Marquette. Elsevier does not grant permission for this article to be further copied/distributed or hosted elsewhere without the express permission from Elsevier.

\section{Thermal degradation of polystyrene, poly(1,4-butadiene) and copolymers of styrene and 1,4-butadiene irradiated under air or argon with 60Co-y-rays}

W. Schnabel

Hahn-Meitner-Institut Berlin GmbH, Bereich Physikalische Chemie, Glienicker Str. 100, D14109 Berlin, Germany

G.F.L evchik

Research Institute for Physical Chemical Problems, Belorussian State University, Leningradskaya 14, Minsk 220080, Belarus

C.A. Wilkie Department of Chemistry, Marquette University, POBox 1881, Milwaukee, WI 53201-1881, USA

D.D.Jiang

Department of Chemistry, Marquette University, POBox 1881, Milwaukee, WI 53201-1881, USA 


\section{S.V.Levchik}

Research Institute for Physical Chemical Problems, Belorussian State University, Leningradskaya 14, Minsk 220080, Belarus

\section{Abstract}

${ }^{60} \mathrm{Co}-\gamma$-irradiated samples of polystyrene (PSt), poly(1,4-butadiene), (PBD), and two poly(styrene-co-butadiene)s containing 25 and $75 \%$ BD were subjected to thermogravimetric analysis (TGA), in the presence and absence of $\mathrm{O}_{2}$. In the case of PSt the irradiation caused a significant shift in Tonset, the onset temperature for mass loss, to higher temperatures, whereas in the cases of the BD-containing polymers irradiation caused a decrease in Tonset (oxic irradiation) or had little or no effect on Tonset (anoxic irradiation). The amount of non-volatile residue formed in the cases of BD-containing polymers was augmented by $\gamma$-irradiation. The improved thermal stability of PSt is attributed to radiation-generated unsaturations acting as depolymerization retardants and/or agents in thermal crosslinking. Radiation-induced crosslinks do not affect the thermal behavior of PSt. In the cases of BD-containing polymers the thermal behavior is predominated by reactions of the carbon-carbon double bonds (crosslinking and cyclization). Radiation-induced chemical alterations, therefore, play a minor role during the thermal decomposition.

\section{Introduction}

Polystyrene (PSt), and poly(1,4-butadiene) (PBD), are members of the family of polymers that predominantly crosslink intermolecularly upon irradiation with ${ }^{60} \mathrm{Co}-\gamma$-rays or fast electrons $\frac{1}{2}, \underline{2}, \underline{\underline{3}}$, $4, \underline{5}$. Intermolecular crosslinking results in the formation of a three-dimensional network and, consequently, causes partial insolubilization of the polymer.

Apart from crosslinking PSt and PBD undergo additional chemical alterations. In the case of PSt unsaturations are formed (conjugated $\mathrm{C}=\mathrm{C}$ bonds in the main chain) and pendant benzene groups are converted into cyclohexadiene groups ${ }^{[4]}$. In the case of PBD unsaturations are destroyed $[5]$. Upon irradiation in the presence of $\mathrm{O}_{2}$ peroxide, hydroperoxide and carbonyl groups are incorporated into the polymers.

The aim of this study was to find out whether the thermal degradation of polystyrene, poly(1,4butadiene) and copolymers consisting of styrene and 1,4-butadiene moieties is affected by chemical alterations that are generated by irradiating the polymers with ${ }^{60} \mathrm{Co}-\gamma$-rays.

\section{Experimental}

\subsection{Materials}

The homopolymers polystyrene (polymerized by a free radical process) and poly-(1,4butadiene) ( $98 \%$ cis) were obtained from Aldrich Chemical Company. The two copolymers poly(styrene-co-butadiene) differ in their contents of the two components. The copolymer being 
rich in styrene $(75 \% \mathrm{St} / 25 \% \mathrm{BD})$ was a gift from Phillips Petroleum, denoted as $\mathrm{Kr} \Phi 1$, and is herein referred to as K-resin. The copolymer being rich in butadiene (25\% St/75\% BD) was a gift from Shell Chemical Company, denoted as Kraton D1102, and is referred to as SBS in this paper. The IR spectra of the copolymers possess a band at $965 \mathrm{~cm}^{-1}$ indicating the presence of trans isomer. The polymers were used as received and films were pressed by compression of the polymer beads at a temperature between 120 and $160^{\circ} \mathrm{C}$ and a pressure of about $10^{8} \mathrm{~Pa}\left(1.5 \times 10^{4} \mathrm{psi}\right) . \underline{\text { Table } 1}$ presents a list of the polymers and their weight average molar mass.

Table 1. Polymers used in this work

\begin{tabular}{|c|c|c|c|}
\hline Polymer & $\begin{array}{l}\text { Acronym (sample } \\
\text { denotation) }\end{array}$ & Composition (mol\%) & $\begin{array}{l}M w^{a}(g \\
\left.m o l^{-1}\right)\end{array}$ \\
\hline Polystyrene & PSt (S) & styrene (100) & $2.8 \times 10^{5}$ \\
\hline $\begin{array}{l}\text { Poly(1,4-butadiene) (98\% } \\
\text { cis) }\end{array}$ & $\operatorname{PBD}(\mathrm{P})$ & butadiene (100) & $2-3 \times 10^{6}$ \\
\hline Poly(styrene-co-butadiene) & $\mathrm{K}-\operatorname{Re} \sin (\mathrm{K})$ & $\begin{array}{l}\text { styrene (75), butadiene } \\
\text { (25) }\end{array}$ & $5-10 \times 10^{3}$ \\
\hline Poly(styrene-co-butadiene) & SBS (B) & $\begin{array}{l}\text { styrene (25), butadiene } \\
\text { (75) }\end{array}$ & $5-10 \times 10^{5}$ \\
\hline
\end{tabular}

${ }^{a}$ Weight average molar mass.

\subsection{Irradiation of polymer samples}

The polymer samples were irradiated in glass ampoules at the ${ }^{60} \mathrm{Co}-\gamma$-source of the HahnMeitner-Institute. The absorbed dose rate as determined by the Fricke dosimeter was $2.4 \mathrm{kGy} \mathrm{h}^{-1}$. The irradiation was performed either under air or under argon. In the latter case the glass ampoules containing the polymer were attached to a high vacuum line and degassed for $24 \mathrm{~h}$. Subsequently, the ampoules were filled with argon and irradiated.

\subsection{Thermogravimetric analysis}

A thermoanalyzer (Mettler, model 3000) was used for both thermogravimetric analysis and differential scanning calorimetry. Thermograms were recorded at a heating rate of $10^{\circ} \mathrm{C} \mathrm{min}-1$ under either air or argon atmosphere.

\subsection{Determination of gel content and swelling ratio}

The gel content and the swelling ratio were determined through a $10 \mathrm{~h}$ Soxhlet extraction with chloroform. The gel content is the mass fraction which is insoluble in the solvent and is determined by taking the ratio of the mass of the thoroughly dried sample after extraction to the mass of the starting polymer. The swelling ratio is a measure of the crosslink density and is determined by placing the extracted sample in a sealed container immediately after extraction 
and then taking the ratio of its mass to that of the starting sample. The greater the swelling ratio, the lower is the crosslink density $\underline{\underline{6}}, \underline{7}, \underline{\underline{g}}, \underline{9}, \underline{\underline{10}}$.

\section{Experimental results}

\subsection{Thermal degradation of unirradiated homo- and copolymers}

The thermal stability of the two homopolymers, PSt and PBD, differs appreciably: PSt undergoes mass loss at temperatures exceeding $300^{\circ} \mathrm{C}$ whereas PBD is thermally stable up to about $400^{\circ} \mathrm{C}$. Interestingly, the thermal stability of the copolymers K-resin (75\% St) and SBS ( $25 \% \mathrm{St}$ ) reflects the composition, i.e. the lower is the St content the higher is the temperature at which degradation commences. In other words the thermal stability increases in the series $\mathrm{PSt}<\mathrm{K}$-resin < SBS < PBD. This can be seen from Fig. 1Fig. 2Fig. 3Fig. 4, which present TGA curves recorded with both the unirradiated and the irradiated polymers. The dependence of the thermostability of the four polymers on the content of styrene moieties is at best characterized in terms of $T_{10 \%}$, i.e. the temperature for $10 \%$ mass loss. It can be seen from Table 2 that, in the case of PSt $T_{10 \%}=315^{\circ} \mathrm{C}$ and in the case of PBD $T_{10 \%}=426^{\circ} \mathrm{C}$. The $T_{10 \%}$ values of the copolymers are intermediate. Moreover, it can be seen from Table 2 that all four polymers begin to decompose at higher temperatures when heated in the absence of oxygen.

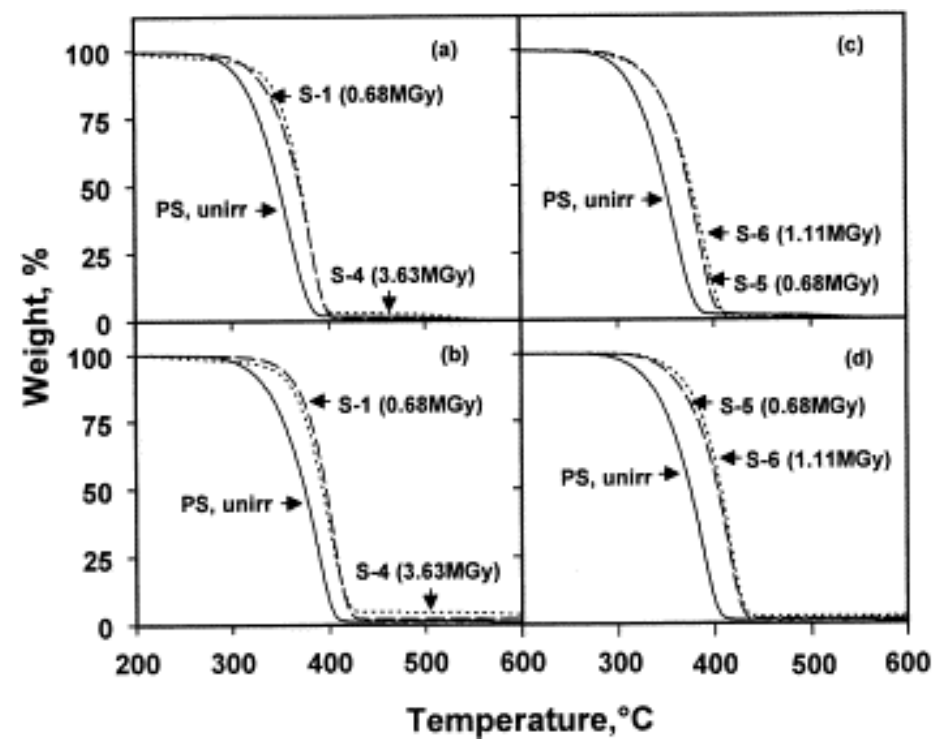

Fig. 1. Thermal gravimetric analysis of polystyrene irradiated with ${ }^{60} \mathrm{Co}-\gamma$-rays. (a) Oxic irradiation, oxic TGA, (b) oxic irradiation, anoxic TGA, (c) anoxic irradiation, oxic TGA; (d) anoxic irradiation, anoxic TGA. 


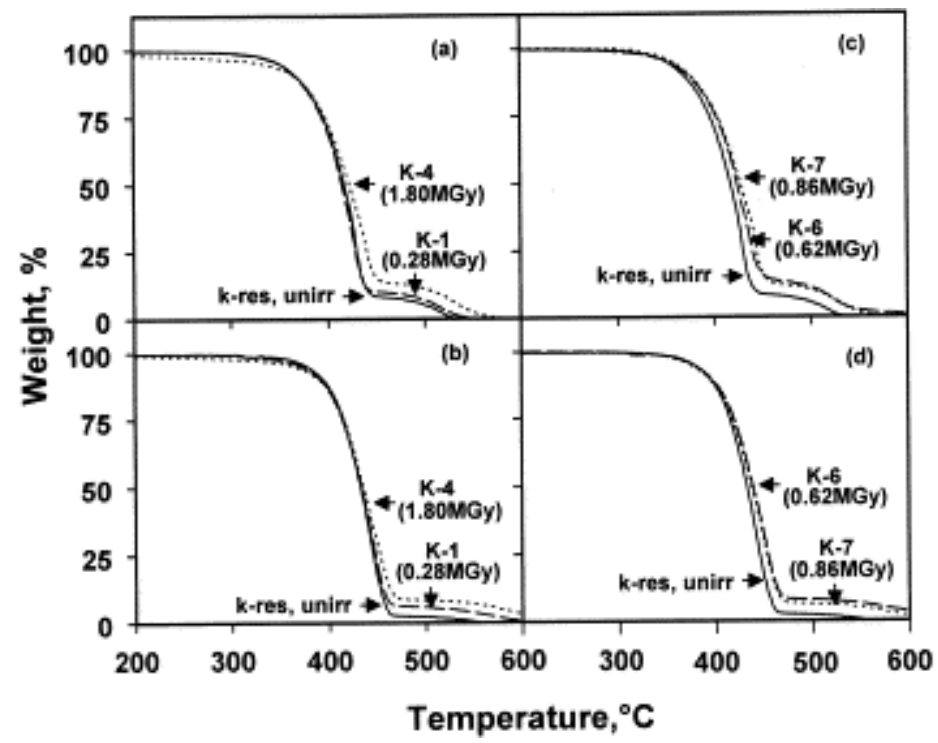

Fig. 2. Thermal gravimetric analysis of K-resin irradiated with ${ }^{60} \mathrm{Co}-\gamma$-rays. (a) Oxic irradiation, oxic TGA; (b) oxic irradiation, anoxic TGA; (c) anoxic irradiation, oxic TGA; (d) anoxic irradiation, anoxic TGA.

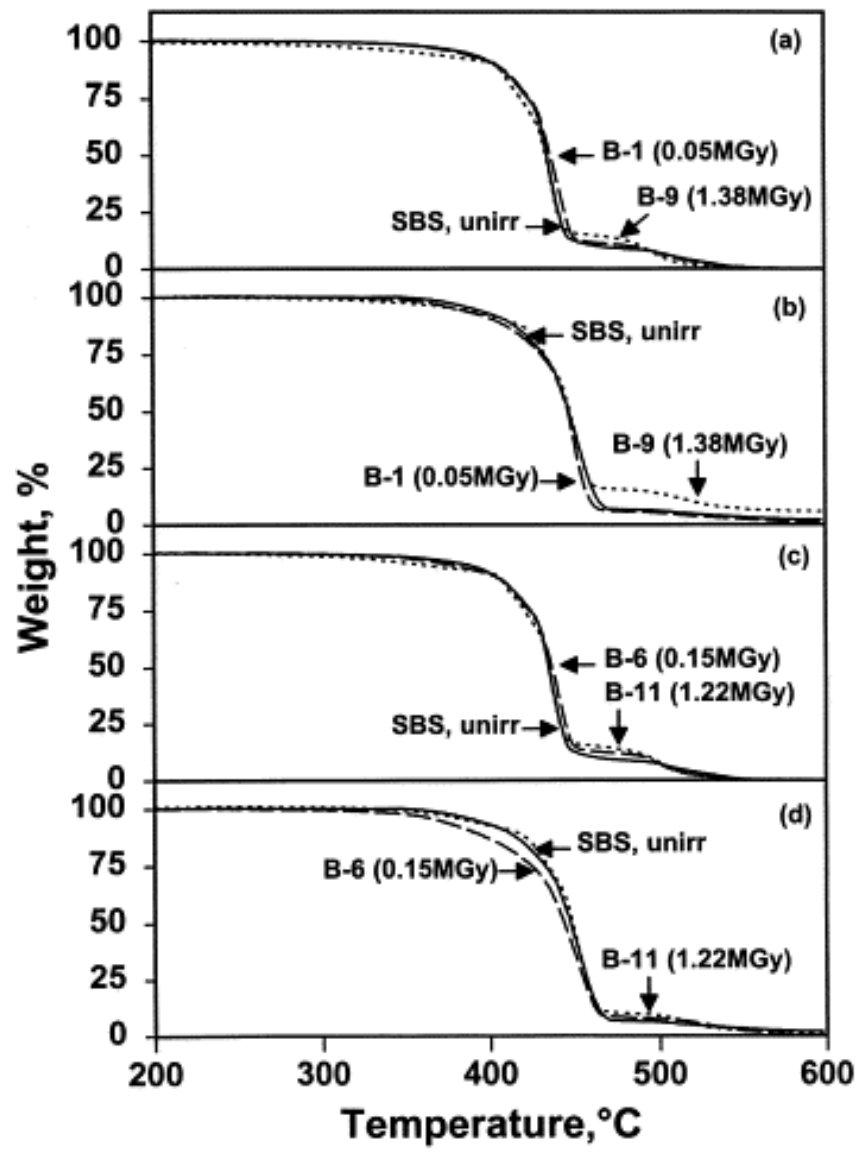

Fig. 3. Thermal gravimetric analysis of SBS polymer irradiated with ${ }^{60} \mathrm{Co}-\gamma$-rays. (a) Oxic irradiation, oxic TGA; (b) oxic irradiation, anoxic TGA; (c) anoxic irradiation, oxic TGA; (d) anoxic irradiation, anoxic TGA. 


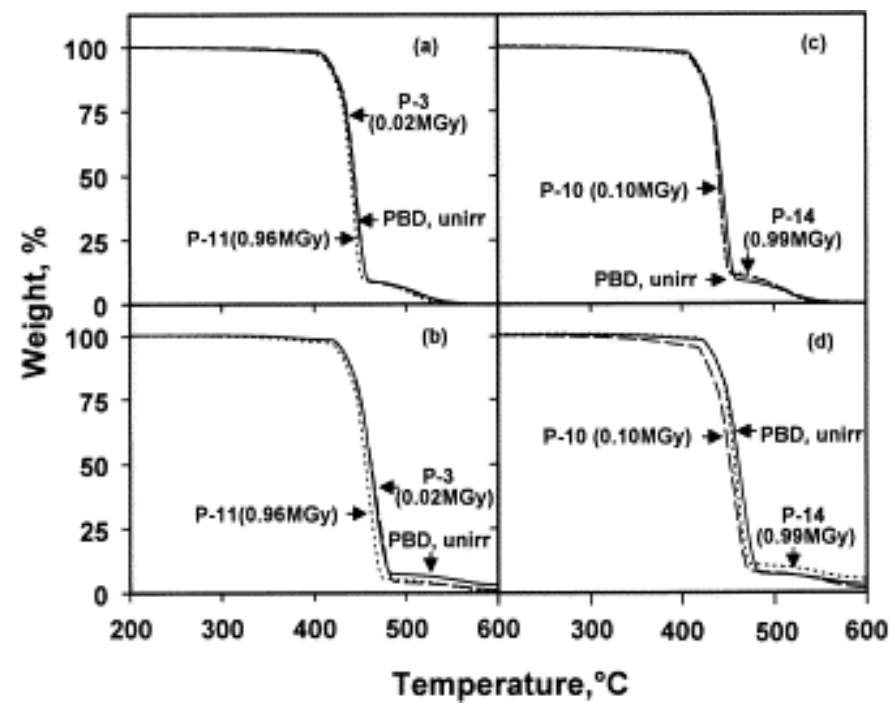

Fig. 4. Thermal gravimetric analysis of poly(1,4-butadiene) irradiated with ${ }^{60} \mathrm{Co}-\gamma$-rays. (a) Oxic irradiation, oxic TGA; (b) oxic irradiation, anoxic TGA; (c) anoxic irradiation, oxic TGA; (d) anoxic irradiation, anoxic TGA.

Table 2. $T_{10 \%}$ values (in ${ }^{\circ} \mathrm{C}$ ) of unirradiated homo- and copolymers

\begin{tabular}{|lllll|}
\hline TGA condition & PSt (0\% BD) & K-Resin (25\% BD) & SBS (75\% BD) & PBD (100\% BD) \\
Oxic & 315 & 369 & 405 & 426 \\
Anoxic & 346 & 394 & 419 & 439 \\
\hline
\end{tabular}

Apart from the difference in the decomposition temperature there is also a significant difference in the course of the decomposition of the two homopolymers. This becomes obvious by comparing the TGA curves recorded with the unirradiated polymers. In the case of PSt the curve falls steadily to zero after mass loss has commenced. By contrast, in the case of PBD, the course of the curve becomes unsteady at temperatures exceeding about $480^{\circ} \mathrm{C}$ indicating that the rate of mass loss is retarded and a non-volatile residue is formed. At $500^{\circ} \mathrm{C}$ the latter amounts to $6 \mathrm{wt} . \%$ and $8 \mathrm{wt} . \%$, when the thermolysis is performed under air or argon, respectively. Obviously, the discontinuity in the TGA curves shows that upon heating PBD is transformed into a material of higher thermal stability. Noticeably, also the TGA curves recorded with the two copolymers exhibit a discontinuity at higher temperatures. In the cases of K-resin and SBS the rate of mass loss is strongly retarded at $T>430^{\circ} \mathrm{C}$ and at $T>450^{\circ} \mathrm{C}$, respectively, as can be seen from Fig. 2 and Fig. 3 , respectively.

The differences in the course of the decomposition of the two homopolymers, PSt and PBD, were also reflected by differential scanning calorimetry performed under argon atmosphere as can be seen from Fig. 5 and Fig. 6 respectively. The DSC curve of PSt exhibits only an endothermic peak at $396^{\circ} \mathrm{C}$ while that of PBD shows exothermic features around 220 and $400^{\circ} \mathrm{C}$. The latter is followed by an endothermic peak near $500^{\circ} \mathrm{C}$ which apparently corresponds to the discontinuity in the TGA curve. Based upon earlier work on the thermal 
degradation of $\mathrm{PBD} \underline{11}, \underline{12}, \underline{13}, \underline{14}, \underline{15}, \underline{16}$, one can assign the exotherm near $400^{\circ} \mathrm{C}$ to cyclization reactions. The assignment of the exotherm near $220^{\circ} \mathrm{C}$ is uncertain. Reportedly $\frac{12]}{\text {, cis } \rightarrow \text { trans }}$ isomerization occurs at this temperature range. However, this process is thought to be endothermic. The DSC curves recorded with the two copolymers, SBS and K-resin shown in Fig. 7 and Fig. 8 respectively, exhibited both endo- and exothermic features, the latter very likely reflecting the discontinuity in the TGA curves.

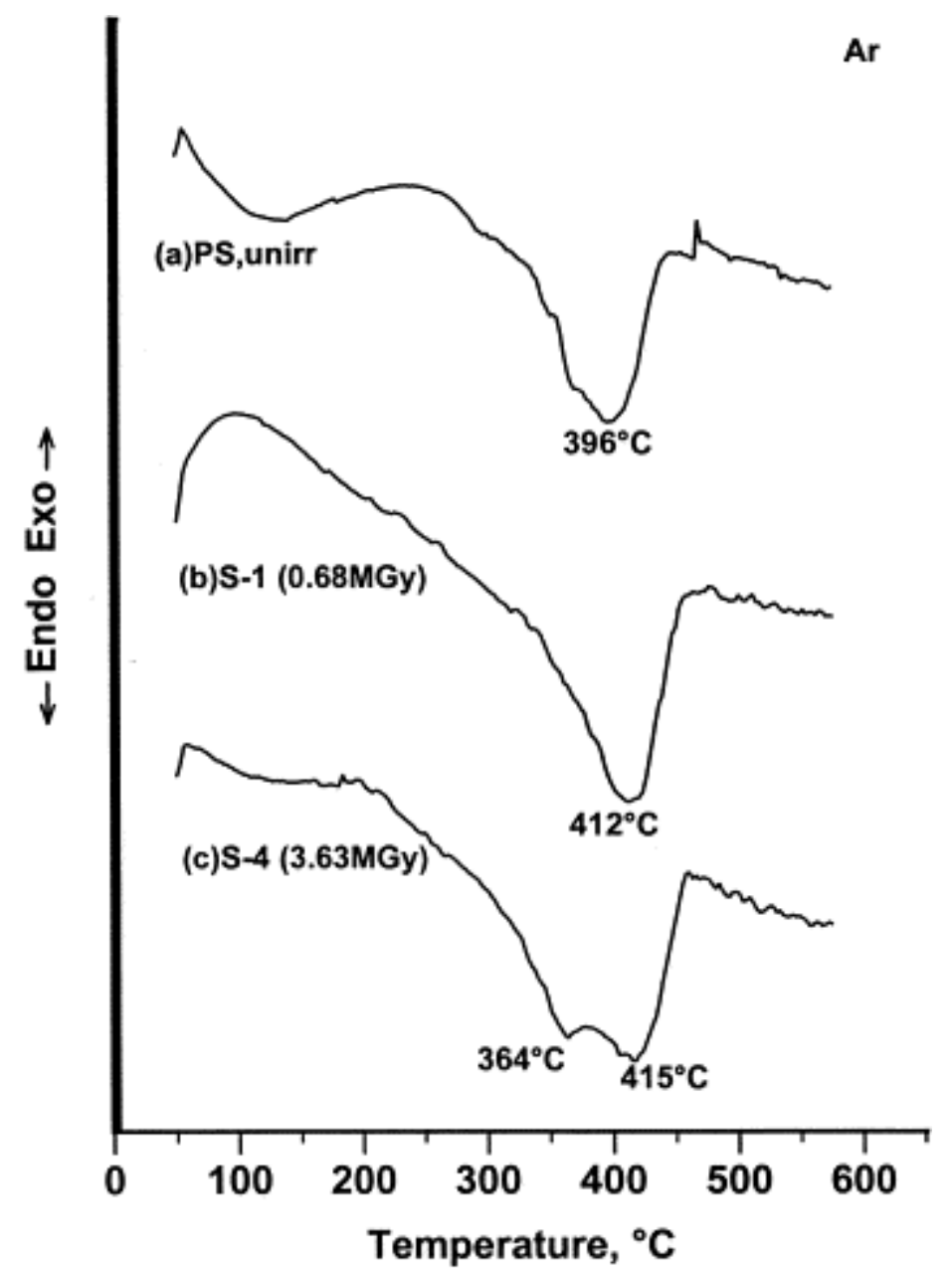

Fig. 5. Differential scanning calorimetry of unirradiated and irradiated polystyrene performed under argon atmosphere. 


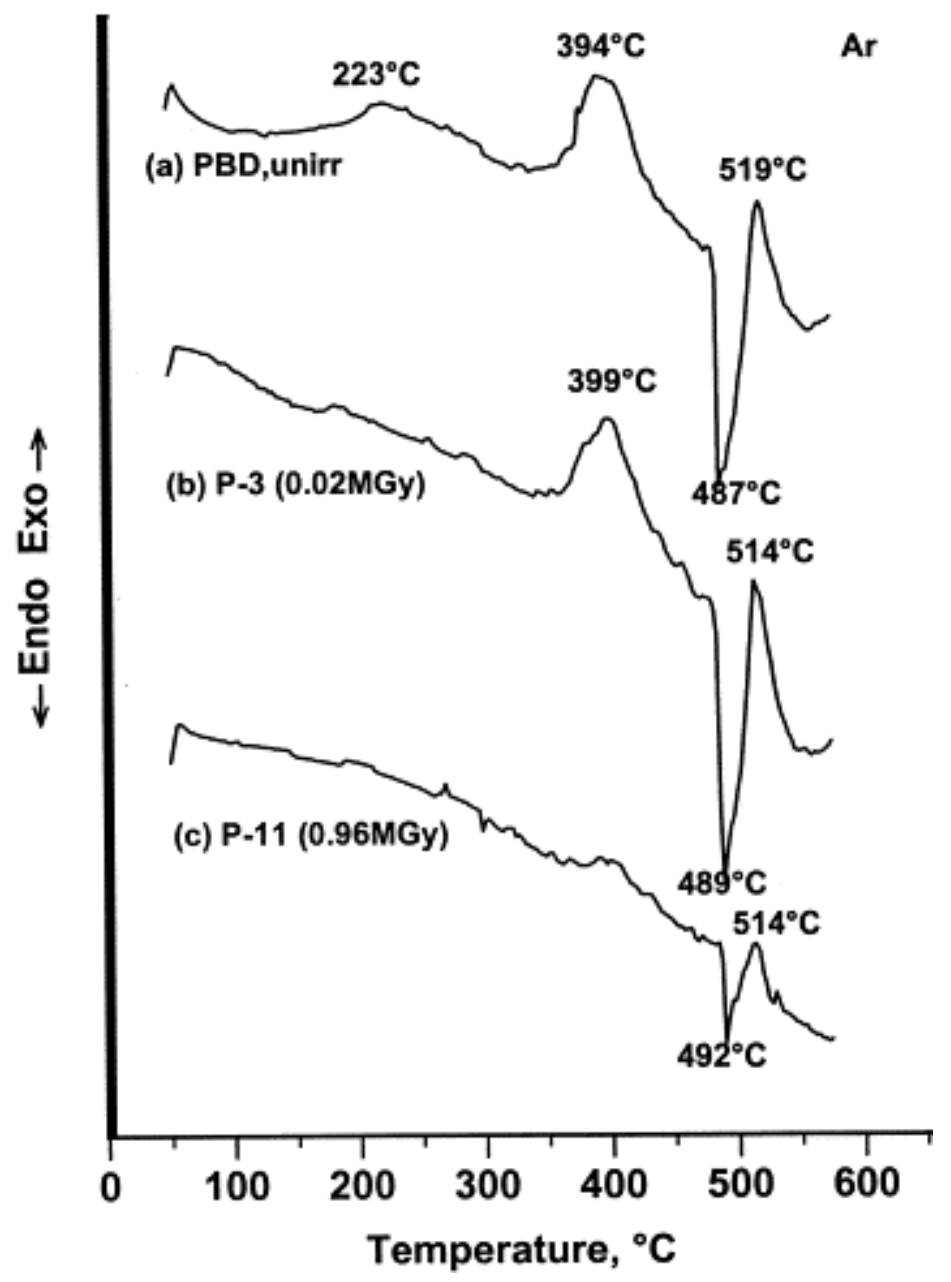

Fig. 6. Differential scanning calorimetry of unirradiated and irradiated poly(1,4-butadiene) performed under argon atmosphere. 


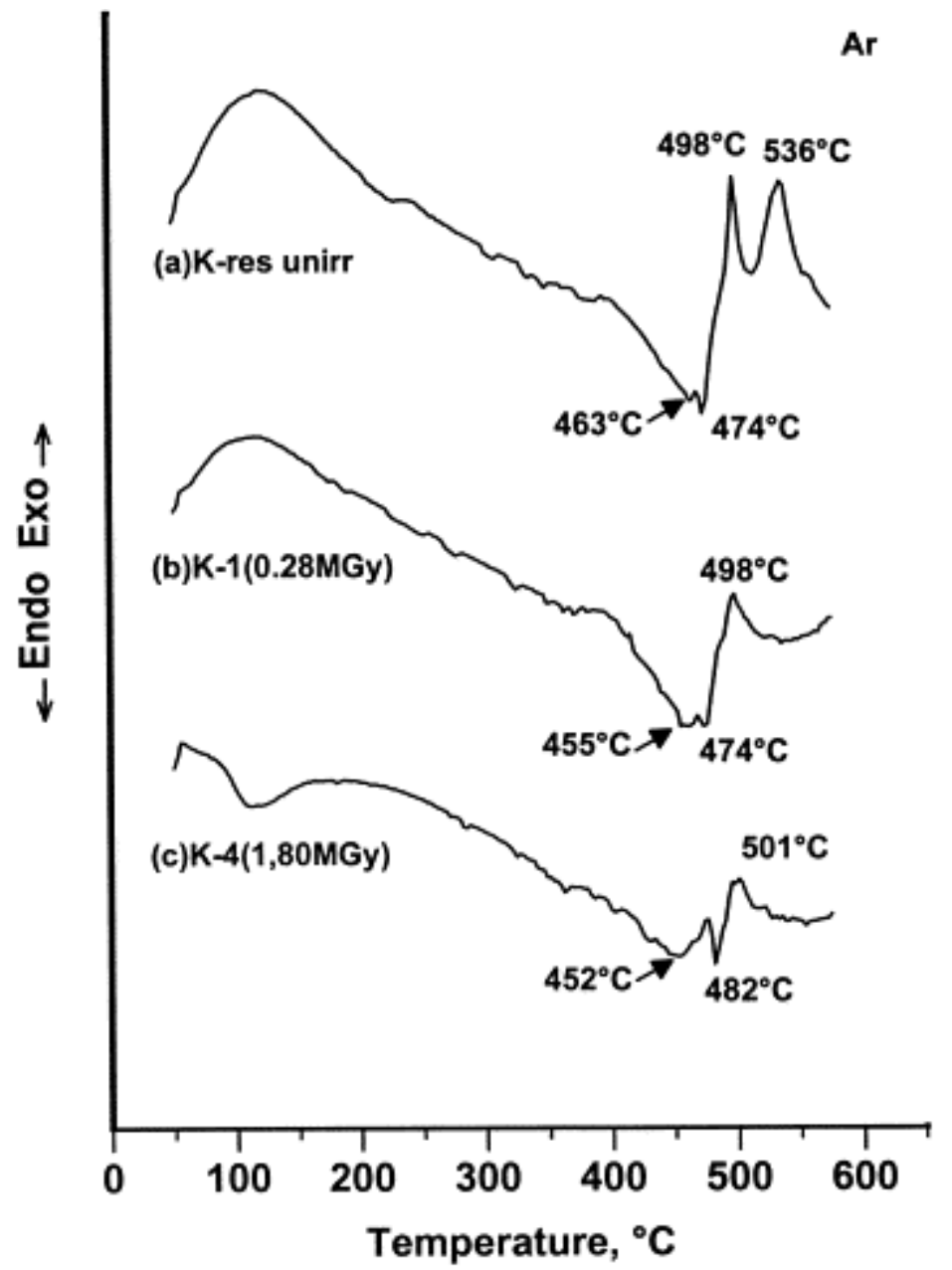

Fig. 7. Differential scanning calorimetry of unirradiated and irradiated K-resin samples performed under argon atmosphere. 


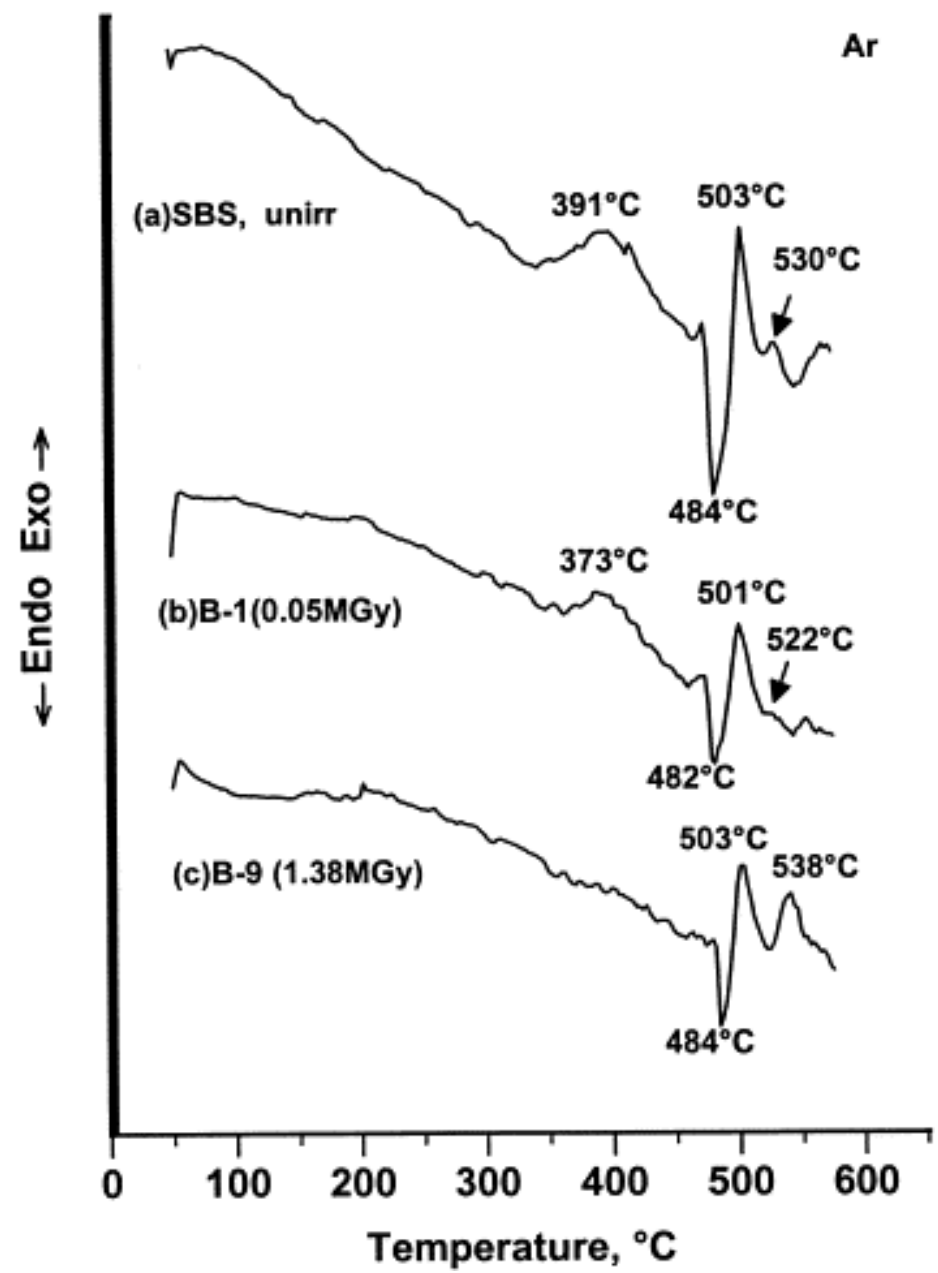

Fig. 8. Differential scanning calorimetry of unirradiated and irradiated SBS samples performed under argon atmosphere.

The difference in the thermal stability and in the course of the decomposition of the two homopolymers observed in this work is well known and in this connection credit has to be given to earlier work concerning the thermal degradation of PBD $\underline{11}, \underline{12}, \underline{13}, \underline{14}, \underline{15}, \underline{16}$, of PSt $\underline{17}, \underline{18}, \underline{19}$, $\underline{20}, \underline{21}, \underline{22}, \underline{23}, \underline{24}, \underline{25}$ and PBD-PSt copolymer. $\underline{26}, \underline{27}$

\subsection{Thermal degradation of irradiated homo- and copolymers}

\subsubsection{Polystyrene}

The TGA curves recorded with PSt irradiated with ${ }^{60} \mathrm{Co}-\gamma$-rays under air are shifted to higher temperatures relative to the curve obtained with the unirradiated polymer. This can be seen from Fig. 1(a) and Fig. 1(b) and from Table 3. Notably, $T_{10 \%}$ increased with increasing absorbed dose (up to about $2 \mathrm{MGy}$ ) from 315 to $360^{\circ} \mathrm{C}$ when the TGA curves were recorded under air. Similarly, $T_{10 \%}$ increased from 346 to $371^{\circ} \mathrm{C}$ when the TGA curves were recorded under argon. At a much higher dose (3.6 MGy) this trend reverses. Analogous results were obtained with PSt samples irradiated under argon [see Fig. 1(c) and Fig. 1(d)]. Table 4 shows that $T_{10 \%}$ increased from 315 to $338^{\circ} \mathrm{C}$ at $1.1 \mathrm{MGy}$, and from 346 to $368^{\circ} \mathrm{C}$ at $1.1 \mathrm{MGy}$ when 
the TGA curves were recorded under air or argon, respectively. The DSC curves shown in Fig. $\underline{5}$ demonstrate that the temperature for endothermic degradation increases upon mild irradiation ( $0.68 \mathrm{MGy})$ by $16^{\circ} \mathrm{C}$. The glass transition which occurs near $100^{\circ} \mathrm{C}$ is not observed in this study. At a significantly larger absorbed dose (3.63 MGy) two endothermic features are observed, one at a temperature lower and one at a temperature higher than that observed in the case of unirradiated PSt.

Table 3. Thermal degradation of polystyrene irradiated under air with ${ }^{60} \mathrm{Co}-\gamma$-rays. Data obtained from TGA curves recorded at a scan rate of $10^{\circ} \mathrm{C} \mathrm{min}-1$

\begin{tabular}{|llllll|}
\hline Sample no. & Atmosphere & $D$ abs $(\mathrm{MGy})$ & GC $\underline{\underline{a}}(\mathrm{wt} \%)$ & $T_{10 \%} \underline{\underline{\underline{b}}}\left({ }^{\circ} \mathrm{C}\right)$ & $\mathrm{NVR}^{\mathrm{c}}(\mathrm{wt} \%)$ \\
& Air & 0 & 0 & 315 & 0 \\
S-1 & Air & 0.68 & 0 & 339 & 0 \\
S-2 & Air & 1.29 & 0 & 351 & 0 \\
S-3 & Air & 2.15 & 0 & 360 & 1 \\
S-4 & Air & 3.63 & 0 & 336 & 2 \\
S-1 & Ar & 0 & 0 & 346 & 2 \\
S-2 & Ar & 0.68 & 0 & 371 & 2 \\
S-3 & Ar & 1.29 & 0 & 368 & 3 \\
S-4 & Ar & 2.15 & 0 & 371 & 2 \\
\hline
\end{tabular}

${ }^{\mathrm{a}} \mathrm{Gel}$ content.

${ }^{\mathrm{b}}$ Temperature for $10 \mathrm{wt} \%$ mass loss.

${ }^{\mathrm{C}}$ Non-volatile residue at $500^{\circ} \mathrm{C}$

Table 4. Thermal degradation of polystyrene irradiated under argon with ${ }^{60} \mathrm{Co}-\gamma$-rays. Data obtained from TGA curves recorded at a scan rate of $10^{\circ} \mathrm{C} \mathrm{min}-1$

\begin{tabular}{|llllll|}
\hline Sample no. & Atmosphere & $D_{\text {abs }(\mathrm{MGy})}$ & $\mathrm{GC}(\mathrm{wt} \%)^{\underline{a}}$ & $T_{10 \%}\left({ }^{\circ} \mathrm{C}\right)^{\underline{\underline{b}}}$ & $\left.\mathrm{NVR}^{\mathrm{w}} \mathrm{wt} \%\right)^{\underline{\mathrm{C}}}$ \\
\hline S-5 & Air & 0 & 0 & 315 & 0 \\
S-6 & Air & 0.68 & 0 & 338 & 0 \\
S-8 & Air & 1.11 & $89-100$ & 338 & 0 \\
S & Air & 3.21 & & 323 & 0 \\
S-5 & Ar & 0 & 0 & 346 & 2 \\
S-6 & Ar & 0.68 & 0 & 371 & 3 \\
S-8 & Ar & 1.11 & $98-100$ & 368 & 2 \\
\hline
\end{tabular}

${ }^{\mathrm{a}} \mathrm{Gel}$ content.

${ }^{\mathrm{b}}$ Temperature for $10 \mathrm{wt} \%$ mass loss.

${ }^{\mathrm{c}}$ Non-volatile residue at $500^{\circ} \mathrm{C}$. 
It is to be pointed out that, contrary to the samples irradiated under air, those irradiated under argon were crosslinked as is concluded on the basis of the gel content values listed in the fourth column of Table 3 and Table 4. Obviously, crosslinking does not affect the thermal degradation of polystyrene since quite similar results were obtained with crosslinked and uncrosslinked irradiated samples. Therefore, the increase in the thermal stability of polystyrene reflected by the shift of the TGA curves to higher temperatures must be due to chemical alterations that are not related to crosslinking.

\subsubsection{K-resin}

It has been pointed out above that $\mathrm{K}$-resin is transformed into a material of higher thermal stability at temperatures exceeding $430^{\circ} \mathrm{C}$. Irradiation under air or argon enhances this behavior as can be seen from Fig. 2. The weight fraction, non-volatile at $500^{\circ} \mathrm{C}$, becomes larger with increasing absorbed dose, no matter whether the polymer is irradiated under oxic (air) or anoxic (argon) conditions (Table 5 and Table 6 , 7th column). Apparently, the amount of the radiation-induced augmentation of the non-volatile residue is larger when the thermal degradation takes place in the presence of oxygen. For example, anoxic irradiation to an absorbed dose of $0.86 \mathrm{MGy}$ results in a non-volatile residue of $11 \mathrm{wt} \%$, when the thermal degradation is performed under air compared to only $6 \mathrm{wt} \%$ under argon.

Table 5. Thermal degradation of K-resin irradiated under air with ${ }^{60} \mathrm{Co}-\mathrm{y}$-rays. Data obtained from TGA curves recorded at a scan rate of $10^{\circ} \mathrm{C} \mathrm{min}-1$

\begin{tabular}{|lllllll|}
\hline Sample no. & Atmosphere & $D_{\text {abs }(\text { MGy })}$ & $R_{\text {sw }}(\%)^{\underline{a}}$ & GC (wt\%) $)^{\underline{b}}$ & $T_{10 \%}\left({ }^{\circ} \mathrm{C}\right)^{\underline{c}}$ & NVR (wt\%) \\
\hline & Air & 0 & $\infty$ & 0 & 369 & 5 \\
K-1 & Air & 0.28 & 2100 & 86 & 368 & 6 \\
K-3 & Air & 1.12 & 880 & 75 & 362 & 9 \\
K-4 & Air & 1.80 & 780 & 88 & 368 & 11 \\
- & Ar & 0 & $\infty$ & 0 & 393 & 3 \\
K-4 & Ar & 1.80 & 780 & 88 & 390 & 9 \\
\hline
\end{tabular}

aswelling ratio

${ }^{\mathrm{b}} \mathrm{Gel}$ content.

${ }^{\mathrm{C}}$ Temperature for $10 \mathrm{wt} \%$ mass loss.

${ }^{\mathrm{d}}$ Non-volatile residue at $500^{\circ} \mathrm{C}$.

Table 6. Thermal degradation of K-resin irradiated under argon with ${ }^{60} \mathrm{Co}-\gamma$-rays. Data obtained from TGA curves recorded at a scan rate of $10^{\circ} \mathrm{C} \mathrm{min}-1$

\begin{tabular}{|c|c|c|c|c|c|c|}
\hline Sample no. & Atmosphere & $D_{\text {abs }}$ (MGy) & $R_{\mathrm{sw}}(\%)^{\underline{a}}$ & $\mathrm{GC}(w t \%)^{\underline{b}}$ & $T_{10 \%}\left({ }^{\circ} \mathrm{C}\right)^{\underline{c}}$ & NVR $(w t \%)^{d}$ \\
\hline- & Air & 0 & $\infty$ & 0 & 369 & 5 \\
\hline $\mathrm{K}-6$ & Air & 0.62 & 950 & 99 & 374 & 11 \\
\hline $\mathrm{K}-7$ & Air & 0.86 & 760 & 99 & 376 & 11 \\
\hline
\end{tabular}




\begin{tabular}{|lllllll|}
- & Ar & 0 & $\infty$ & 0 & 394 & 3 \\
K-6 & Ar & 0.62 & 950 & 99 & 395 & 8 \\
K-7 & Ar & 0.86 & 760 & 99 & 392 & 6 \\
\hline
\end{tabular}

aswelling ratio.

${ }^{\mathrm{b}} \mathrm{Gel}$ content.

${ }^{\mathrm{C}}$ Temperature for $10 \mathrm{wt} \%$ mass loss

${ }^{\mathrm{d}}$ Non-volatile residue at $500^{\circ} \mathrm{C}$.

Regarding the temperature of onset in mass loss, irradiation both in air and in argon atmosphere does not result in a clearly measurable effect. This can be seen from Table 5 and Table 6, where the temperature for $10 \mathrm{wt} \%$ mass loss is listed in the 6th column.

The DSC curve (Fig. 7) shows two radiation-induced changes. In the low temperature region, between 100 and $200^{\circ} \mathrm{C}$, there is an exothermic peak in the case of the unirradiated sample. It becomes less pronounced upon mild irradiation (0.28 MGy). At higher absorbed dose (1.80 MGy) there is an endothermic peak at this position. This behavior corresponds to the early mass loss seen from the TGA curves. At higher temperatures there are small radiationinduced changes in position and intensity of the thermal events. These changes may be correlated with the changes in the amount of non-volatile residue, which are observed.

The results do not allow a conclusion concerning the relation between radiation-induced crosslink density and thermal stability. Remarkably, K-resin is crosslinked both under oxic and anoxic irradiation as is inferred from the gel data listed in the fifth column of Table 5 and Table $\underline{6}$.

\subsubsection{SBS}

Irradiation both under air and under argon generates intermolecular crosslinks which is concluded from the gel data listed in the fifth column of Table 7 and Table 8: almost total insolubilization is attained at relatively low absorbed dose. However, oxygen retards crosslinking, i.e. total insolubilization requires a higher absorbed dose in the case of oxic than in the case of anoxic irradiation.

Table 7. Thermal degradation of SBS polymer irradiated under air with ${ }^{60} \mathrm{Co}-\gamma$-rays. Data obtained from TGA curves recorded at a scan rate of $10^{\circ} \mathrm{C} \mathrm{min}-1$

\begin{tabular}{|lllllll|}
\hline Sample no. & Atmosphere & Dabs (MGy) & $R_{\text {sw }}(\%)^{\underline{a}}$ & $\mathrm{GC}_{(\mathrm{wt} \%)^{\underline{\mathrm{b}}}}$ & $T_{10 \%}\left({ }^{\circ} \mathrm{C}\right)^{\underline{\mathrm{c}}}$ & $\mathrm{NVR}(\mathrm{wt} \%)^{\underline{\underline{d}}}$ \\
\hline & Air & 0 & $\infty$ & 0 & 403 & 8 \\
B-1 & Air & 0.05 & $\infty$ & 0 & 404 & 10 \\
B-4 & Air & 0.21 & 1990 & 94 & 383 & 14 \\
B-9 & Air & 1.38 & & & 404 & 15 \\
- & Ar & 0 & $\infty$ & 0 & 410 & 6 \\
B-1 & Ar & 0.05 & $\infty$ & 0 & 403 & 6
\end{tabular}




\begin{tabular}{|lllllll|}
$\mathrm{B}-4$ & $\mathrm{Ar}$ & 0.21 & 1990 & 94 & 395 & 6 \\
$\mathrm{~B}-9$ & $\mathrm{Ar}$ & 1.38 & & & 410 & 15 \\
\hline
\end{tabular}

aswelling ratio.

${ }^{\text {b}}$ Gel content.

${ }^{\mathrm{c}}$ Temperature for $10 \mathrm{wt} \%$ mass loss.

${ }^{\mathrm{d}}$ Non-volatile residue at $480^{\circ} \mathrm{C}$.

Table 8. Thermal degradation of SBS polymer irradiated under argon with ${ }^{60} \mathrm{Co}-\gamma$-rays. Data obtained from TGA curves recorded at a scan rate of $10^{\circ} \mathrm{C} \mathrm{min}{ }^{-1}$

\begin{tabular}{|lllllll|}
\hline Sample no. & Atmosphere & $D_{\text {abs }}(\mathrm{MGy})$ & $R_{\mathrm{sw}}(\%)^{\underline{a}}$ & $\mathrm{GC}(\mathrm{wt} \%)^{\underline{\underline{b}}}$ & $T_{10 \%}\left({ }^{\circ} \mathrm{C}\right)^{\underline{\mathrm{c}}}$ & $\mathrm{NVR}^{(\mathrm{wt} \%)^{\underline{d}}}$ \\
& Air & 0 & $\infty$ & 0 & 403 & 8 \\
B-5 & Air & 0.10 & 3500 & 86 & 398 & 9 \\
B-6 & Air & 0.15 & 1300 & 99 & 403 & 12 \\
B-10 & Air & 0.86 & 400 & 96 & 409 & 9 \\
B-11 & Air & 1.22 & 400 & 99 & 404 & 10 \\
- & Ar & 0 & $\infty$ & 0 & 410 & 6 \\
B-5 & Ar & 0.10 & 3500 & 86 & 399 & 6 \\
B-6 & Ar & 0.15 & 1300 & 99 & 389 & 6 \\
B-10 & Ar & 0.86 & 400 & 96 & 417 & 9 \\
B-11 & Ar & 1.22 & 400 & 99 & 414 & 10 \\
\hline
\end{tabular}

aswelling ratio.

${ }^{\mathrm{b}} \mathrm{Gel}$ content

${ }^{\mathrm{c}}$ Temperature for $10 \mathrm{wt} \%$ mass loss.

${ }^{\mathrm{d}}$ Non-volatile residue at $480^{\circ} \mathrm{C}$.

The onset temperature for mass loss is hardly affected by $\gamma$-irradiation although mild irradiation seems to have a decreasing effect. This can be seen from the 6th column of Table 7 and Table $\underline{8}$, where the temperature for $10 \%$ mass loss is listed. This behavior is independent of the irradiation condition (anoxic or oxic) and was observed at thermolysis both under air and argon. As found in the case of K-resin, the non-volatile residue (here at $480^{\circ} \mathrm{C}$ ) determined during the thermolysis under air, was augmented with increasing absorbed dose. Nearly constant residual fractions were found with mildly irradiated (up to $0.21 \mathrm{MGy}$ ) and unirradiated samples of SBS polymer thermolyzed under Ar. However, the non-volatile residue was 2.5 times larger when the absorbed dose was increased to $1.38 \mathrm{MGy}$. Similar observations were made when SBS was irradiated under argon. This can be seen also from Table 7 and Table 8 (7th column).

The DSC curve undergoes only subtle changes upon irradiation as can be seen from Fig. 8. An exothermic feature at $391^{\circ} \mathrm{C}$ present in the case of the unirradiated sample moves to $373^{\circ} \mathrm{C}$ at $D_{\text {abs }}=0.05 \mathrm{MGy}$ and completely disappears at $D_{\mathrm{abs}}=1.38 \mathrm{MGy}$. At this rather high absorbed 
dose there is a relatively strong exothermic feature at $538^{\circ} \mathrm{C}$ which very likely is related to the formation of the non-volatile residue.

\subsubsection{Poly(1,4-butadiene)}

Irradiation under air or argon induces intermolecular crosslinking as is inferred from the gel data in the fifth column of Table 9 and the fourth column of Table 10: almost total insolubilization is attained already at relatively low absorbed dose. The thermal behavior of irradiated poly(1,4-butadiene) differs only slightly from that of the unirradiated polymer. From Table 9 it is seen that oxic irradiation results in a decrease in the onset temperature and in a slight increase in the fraction being non-volatile at $500^{\circ} \mathrm{C}$, provided the polymer is heated under air. Upon heating under argon irradiated poly(1,4-butadiene) starts to decompose earlier, i.e. at a lower temperature than the unirradiated polymer, but the non-volatile fraction is unaffected. Table 10 demonstrates that anoxic irradiation hardly affects the thermal behavior of poly(1,4-butadiene). The temperature for $10 \mathrm{wt} \%$ mass loss remains constant up to the highest applied absorbed dose (0.96 MGy), but the non-volatile residue $\left(\right.$ at $\left.500^{\circ} \mathrm{C}\right)$ is somewhat augmented. Apparently, there is no effect of crosslink density on the onset of degradation or on the amount of non-volatile residue.

Table 9. Thermal degradation of poly(1,4-butadiene) irradiated under air with ${ }^{60} \mathrm{Co}-\gamma$-rays. Data obtained from TGA curves recorded at a scan rate of $10^{\circ} \mathrm{C} \mathrm{min}-1$

\begin{tabular}{|c|c|c|c|c|c|c|}
\hline Sample no. & Atmosphere & $D_{\text {abs }}$ (MGy) & $R_{\mathrm{sw}}(\%)^{\mathrm{a}}$ & $\mathrm{GC}(w t \%)^{\underline{b}}$ & $T_{10 \%}\left({ }^{\circ} \mathrm{C}\right) \underline{\mathrm{c}}$ & NVR (wt\%) \\
\hline - & Air & 0 & $\infty$ & 0 & 426 & 6 \\
\hline P-3 & Air & 0.02 & 2500 & 99 & 426 & 6 \\
\hline P-4 & Air & 0.10 & 1200 & 99 & 416 & 9 \\
\hline P-2 & Air & 0.29 & 1200 & 98 & 416 & 7 \\
\hline P-10 & Air & 0.33 & 700 & 99 & 420 & 8 \\
\hline P-11 & Air & 0.96 & 300 & 99 & 420 & 8 \\
\hline- & $\mathrm{Ar}$ & 0 & $\infty$ & 0 & 439 & 8 \\
\hline P-3 & $\mathrm{Ar}$ & 0.02 & 2500 & 99 & 423 & 4 \\
\hline P-4 & $\mathrm{Ar}$ & 0.10 & 1200 & 99 & 423 & 8 \\
\hline P-2 & $\mathrm{Ar}$ & 0.29 & 1200 & 98 & 423 & 8 \\
\hline P-10 & $\mathrm{Ar}$ & 0.33 & 700 & 99 & 423 & 6 \\
\hline B-11 & $\mathrm{Ar}$ & 0.96 & 300 & 99 & 423 & 6 \\
\hline
\end{tabular}

${ }^{a}$ Swelling ratio.

${ }^{\mathrm{b}} \mathrm{Gel}$ content.

${ }^{\mathrm{c}}$ Temperature for $10 \mathrm{wt} \%$ mass loss.

${ }^{\mathrm{d}}$ Non-volatile residue at $500^{\circ} \mathrm{C}$. 
Table 10. Thermal degradation of poly(1,4-butadiene) irradiated under argon with ${ }^{60} \mathrm{Co}-\gamma$-rays. Data obtained from TGA curves recorded at a scan rate of $10^{\circ} \mathrm{C} \mathrm{min}-1$

\begin{tabular}{|c|c|c|c|c|c|}
\hline Sample no. & Atmosphere & $D_{\text {abs }}$ (MGy) & $\mathrm{GC}(w t \%)^{\mathrm{a}}$ & $T_{10 \%}\left({ }^{\circ} \mathrm{C}\right)^{\underline{b}}$ & NVR (wt\%) \\
\hline - & Air & 0 & 0 & 426 & 6 \\
\hline P-9 & Air & 0.10 & 99 & 422 & 5 \\
\hline P-13 & Air & 0.63 & & 426 & 8 \\
\hline P-14 & Air & 0.99 & 98 & 426 & 8 \\
\hline - & $\mathrm{Ar}$ & 0 & 0 & 439 & 8 \\
\hline P-9 & $\mathrm{Ar}$ & 0.10 & 99 & 439 & 8 \\
\hline$P-13$ & Ar & 0.63 & & 439 & 8 \\
\hline P-14 & $\mathrm{Ar}$ & 0.99 & 98 & 439 & 10 \\
\hline
\end{tabular}

${ }^{\mathrm{a}} \mathrm{Gel}$ content.

${ }^{\mathrm{b}}$ Temperature for $10 \mathrm{wt} \%$ mass loss.

${ }^{\mathrm{C}}$ Non-volatile residue at $500^{\circ} \mathrm{C}$.

A comparison of the DSC curves of irradiated and unirradiated PBD shown in Fig. 6 reveals an obvious change and this is the disappearance of the exothermic features at 220 and $394^{\circ} \mathrm{C}$ upon irradiation.

\subsection{Conclusions}

On the basis of the TGA curves recorded under oxic and anoxic condition with polymer samples irradiated in the presence and absence of $\mathrm{O}_{2}$ the following conclusions can be drawn (Table 11):

Onset temperature for mass loss: ${ }^{60} \mathrm{Co}-\gamma$-irradiation performed under air or argon improves the thermal stability of polystyrene but deteriorates that of poly(1,4-butadiene) and poly(styrene-co-butadiene). Actually, ${ }^{60} \mathrm{Co}-\gamma$-y-irradiation caused a shift in $T$ onset to higher temperatures in the case of PSt. In the cases of PBD and the copolymers $T$ onset decreased or was not affected upon oxic irradiation. Anoxic irradiation led to a decrease in $T$ onset (at low absorbed dose) only in the case of SBS and did not affect $T_{\text {onset }}$ in the cases of $\mathrm{K}$-resin and PBD.

Formation of non-volatile residue: A non-volatile residue was not formed during the thermolysis of both irradiated and non-irradiated polystyrene. However, in the cases of poly(1,4-butadiene) and the two poly(styrene-co-butadiene) samples a non-volatile residue was formed and ${ }^{60} \mathrm{Co}-\gamma$-irradiation caused a significant increase in the formation of non-volatile residue upon thermolysis under air, no matter whether the irradiation was performed under air or under argon. Regarding the anoxic thermolysis ${ }^{60} \mathrm{Co}-\gamma$-irradiation (anoxic and oxic) did not affect the formation of the non-volatile residue in the cases of SBS and PBD (up to $D_{\mathrm{abs}}=0.63 \mathrm{MGy}$ ) but it enhanced the formation of the non-volatile residue in the case of the K-resin. 
Table 11. The effect of ${ }^{60} \mathrm{Co}-\gamma$-irradiation on the thermolysis of polystyrene, poly(1,4-butadiene) and poly(styrene-co-butadiene). Trends of changes in the onset-temperature for mass loss ( $\left.T_{\text {onset }}\right)$ and in the formation of non-volatile residue (NVR) as observed by TGA

\begin{tabular}{|c|c|c|c|c|c|c|c|c|c|}
\hline \multirow[t]{2}{*}{ Irradiation } & \multirow[t]{2}{*}{ Thermolysis } & \multicolumn{2}{|l|}{ PSt } & \multicolumn{2}{|l|}{ K-Resin } & \multicolumn{2}{|l|}{ SBS } & \multicolumn{2}{|l|}{ PBD } \\
\hline & & $T_{\text {onset }}$ & NVR & $T_{\text {onset }}$ & NVR & $T_{\text {onset }}$ & NVR & $T_{\text {onset }}$ & NVR \\
\hline Oxic & Oxic & Increase & None & $\begin{array}{l}\text { No } \\
\text { change }\end{array}$ & Increase & Decrease $^{a}$ & Increase & Decrease & Increase \\
\hline Oxic & Anoxic & Increase & Traces & $\begin{array}{l}\text { No } \\
\text { change }\end{array}$ & Increase & Decrease $^{\mathrm{a}}$ & $\begin{array}{l}\text { No } \\
\text { change }\end{array}$ & Decrease & $\begin{array}{l}\text { No } \\
\text { change }\end{array}$ \\
\hline Anoxic & Oxic & Increase & None & $\begin{array}{l}\text { No } \\
\text { change }\end{array}$ & Increase & $\begin{array}{l}\text { No } \\
\text { change }\end{array}$ & Increase & $\begin{array}{l}\text { No } \\
\text { change }\end{array}$ & Increase \\
\hline Anoxic & Anoxic & Increase & Traces & $\begin{array}{l}\text { No } \\
\text { change }\end{array}$ & Increase & Decrease $^{\mathrm{a}}$ & $\begin{array}{l}\text { No } \\
\text { change }\end{array}$ & $\begin{array}{l}\text { No } \\
\text { change }\end{array}$ & $\begin{array}{l}\text { No } \\
\text { change }{ }^{b}\end{array}$ \\
\hline
\end{tabular}

aAt low absorbed dose.

bUp to $D_{\text {abs }}=0.63 \mathrm{MGy}$, at $D_{\mathrm{abs}}=0.99 \mathrm{MG}$ N NVR was slightly increased.

\section{Discussion}

Regarding the decomposition into volatiles the rather high thermal stability of PBD is noticeable. It is caused by chemical reactions which occur during heating with high yield and transform the polymer largely into another material. The reactions predominantly comprise crosslinking and cyclization. Reportedly, both 1,2- and 1,4-PBD thermally crosslink at $270^{\circ} \mathrm{C}$ thus forming an insoluble gel $\underline{11}, \underline{12}$. Moreover, PBD undergoes cyclization, an exothermic reaction, at $350-370^{\circ} \mathrm{C} \underline{11}, \underline{12}, \underline{13}$. In the case of cis-PBD cyclization is accompanied by cis $\rightarrow$ trans isomerization, an endothermic reaction commencing around $200^{\circ} \mathrm{C}$. At higher temperature $\left(T>450^{\circ} \mathrm{C}\right)$ depolymerization occurs.

Apparently, cyclization occurred at a somewhat higher temperature in the present case since the exothermic peak of the DSC curve of unirradiated PBD is located at $394^{\circ} \mathrm{C}$. Since this peak vanished after irradiation (Fig. 6) it seems that radiation-induced chemical alterations suppress cyclization. In this connection it should be noted that ${ }^{60} \mathrm{Co}-\gamma$-irradiation of cis-PBD causes cis $\rightarrow$ trans isomerization (confirmed by IR-measurements in this work) and a decrease in unsaturation (rather high $G$-value, but nature of products unknown) ${ }^{[5]}$. Therefore, the absence of the DSC exotherm around $220^{\circ} \mathrm{C}$ at $0.96 \mathrm{MGy}$ (Fig. 6) suggests that this peak reflects a reaction of unsaturated groups.

Taking into account the severe thermally induced alterations it becomes comprehensible why the thermal behavior of irradiated PBD differs only slightly from that of the unirradiated polymer. Irradiation of PBD causes intermolecular crosslinking. However, at the absorbed doses applied in this work, the crosslink density attained by $y$-irradiation must be rather low compared to that achieved by thermal crosslinking induced by heating the sample during TGA. Therefore, as far as anoxic irradiation is concerned, the low content of radiation-chemically altered sites in the polymer cannot, or can only minimally affect the thermal behavior of PBD. A somewhat different situation is observed with PBD irradiated in the presence of oxygen. Here, 
oxidized sites, radiation-chemically generated, are likely to impede crosslinking and cyclization to some extent, and this might cause a shift in the onset temperature for mass loss to lower temperatures.

The postulate that there are more crosslinks formed in the course of a TGA experiment than can be achieved by irradiation to the absorbed doses applied in this work has been examined. The gel content $(\mathrm{GC})$ and the swelling ratio $\left(R_{\mathrm{sw}}\right)$ of samples from TGA experiments at various temperatures were determined. When a sample of virgin PBD was heated in a TGA run to $300^{\circ} \mathrm{C} \mathrm{GC}$ was equal to $95 \%$ and $R_{\text {sw }}$ equal to $2500 \%$. Heating to $400^{\circ} \mathrm{C}$ resulted in GC $=100 \%$ and $R_{\mathrm{sw}}=200 \%$. Similar results were obtained with SBS polymer and K-resin. Heating to $400^{\circ} \mathrm{C}$ resulted in GC $=100 \%$ (SBS and K-resin) and $R_{\text {sw }}=300 \%$ (SBS and K-resin). Obviously, these $R_{\mathrm{sw}}$ values are lower or equal to those obtained with samples irradiated to high absorbed doses (Table 5 , Table 6 , Table 7 , Table 8 , Table 9). It is therefore concluded that irradiation is much less effective in generating crosslinks than the thermal treatment during the TGA.

The thermal behavior of PSt differs significantly from that of PBD. According to earlier reviews $\underline{17}, 18$. at $T>300^{\circ} \mathrm{C}, \mathrm{PSt}$ readily undergoes main-chain scission and the free radicals generated in this way initiate depolymerization. In other words, the volatiles consist largely of monomer and oligomers. In contrast to PBD, PSt is not transformed upon heating into a more heat resistant material but it is quite effectively decomposed into volatiles. Radiation-induced chemical alterations are, therefore, very likely to affect the thermal behavior of PSt. The TGA curves recorded with $\gamma$-irradiated PSt clearly demonstrate that this happens. The question now arises as to the nature of these chemical alterations. Since oxic irradiation does not generate crosslinks but also causes a shift in the TGA curve to higher temperature, it can be excluded that radiation-induced intermolecular crosslinks are responsible for the observed increase in the heat resistance of PSt. On the other hand, it has been reported that ${ }^{60} \mathrm{Co}-\gamma$-irradiation generates carbon-carbon double bonds in PSt $\underline{4}, \underline{19}$ and there are two modes of action to be considered in this connection: (a) unsaturated groups can scavenge free radicals generated by main-chain scission and thus inhibit or retard the depolymerization, and (b) the presence of unsaturated groups in the polymer can bring about thermally induced crosslinking reactions that otherwise would not occur. The two modes of action might be strongly interdependent if the free radical formed by the reaction of a terminal macroradical with a carbon-carbon double bond initiates the coupling of unsaturated groups. The speculative nature of this mechanism, which is illustrated in Scheme. 1, is pointed out and further work is necessary to reveal its importance. Some support for this mechanism comes from the fact that both oxic and anoxic irradiation results in an improved thermal resistance of PSt. During irradiation unsaturated groups are formed very rapidly by a non-radical process which implies that $\mathrm{O}_{2}$ cannot interfere with their generation. 

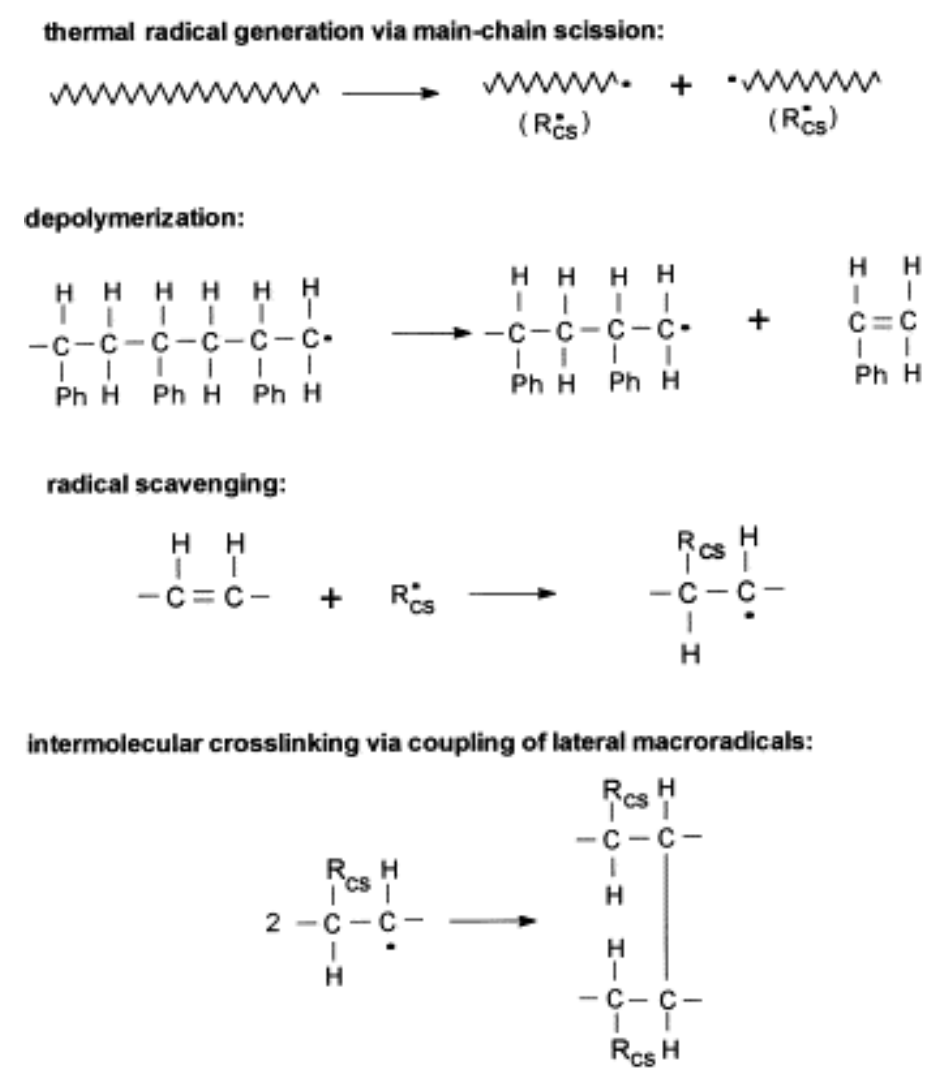

Scheme. 1.

The effects of ${ }^{60} \mathrm{Co}-\gamma$-radiation on the thermolysis of the two copolymers remain to be discussed. Apparently, the butadiene moieties contained in the copolymers determine their thermal behavior. This applies even to the copolymer containing only 25\% BD (K-resin). In other words the reactions discussed with respect to homo PBD, i.e. thermally induced crosslinking and cyclization, occur also in the copolymers and predominantly determine the course of the thermal decomposition. Again, if the mechanism illustrated in Scheme. 1 really applies to the thermolysis of $\gamma$-irradiated PSt and styrene-containing copolymers, the small amount of radiation-induced unsaturation generated in styrene segments of the copolymers should play a negligible role compared to the large amount of unsaturation contained in the butadiene portions of the copolymers.

\section{Acknowledgements}

This work was financially supported in part by a NATO Research Linkage Grant (OUTR.LG 960310).

\section{References}

1 Charlesby A. Atomic radiation and polymers. Oxford: Pergamon Press, 1960.

$\underline{2}$ Chapiro A. Radiation chemistry of polymeric systems. New York: Interscience, 1962. 
$\underline{3}$ Schnabel W. Degradation by high energy radiation. In: Jellinek HHG, editor. Polymer Degradation. Amsterdam: Elsevier Scientific Publ Co., 1978. p. 149.

4 Parkinson WW, Keyser RM. Polystyrene and related polymers. In: Dole M, editor. The radiation chemistry of macromolecules, vol. 2. New York: Academic Press, 1972. p. 57.

5 Böhm GGA. The radiation chemistry of elastomers. In Dole M, editor. The radiation chemistry of macromolecules, vol. 2. New York: Academic Press, 1972. p. 195.

6 O'Donnell JH, Rahman NP, Smith CA. J Polym Sci Polym Chem Ed 1979;17:4081.

7 Flory PJ, Renner, L. J Chem Phys. 1943;11:512.

8 Flory PJ, Renner L. J Chem Phys. 1943;11:521

9 Matsuka K, Tanaka A, Murakami I. Polymer 1984;25:1337.

10 Sircar AK, Lamond TG. J Appl Polym Sci. 1973;17:2569.

11 McCreedy K, Keskkula H. J Appl Polym Sci. 1978;22:999.

12 Golub MA, Gargiulo RJ. J Polym Sci Polym Lett Ed. 1972;10:41.

13 Golub MA. J Polym Sci Polym Lett Ed. 1974;12:615.

14 Grassie N, Heaney A. Eur Polym J. 1974;10:415.

$\underline{15}$ Grassie N, Heaney A. J Polym Sci Polym Lett Ed. 1974;12:89.

16 McCreedy K, Keskkula H. Polymer 1979;20:1155.

17 Madorski SL. Thermal degradation of organic polymers. New York: Interscience, 1964.

18 David C. Thermal degradation of polymers. In: Bamford CH, Tipper CFH, editors.

Degradation of polymers. Comprehensive chemical kinetics, vol. 14. Amsterdam:

Elsevier Scientific Publ Co., 1975.

19 Slovokhotova NA, llicheva ZF, Kargin VA. Vysokomol Soedin 1961;4:19.

20 Cameron GG, Meyer LM, McWalter IT. Macromolecules 1978;11:696.

$\underline{21}$ Chiantore O, Camino G, Costa L, Grassie X. Polym Degrad Stab 1981;3:209.

22 Costa L, Camino G, Guyot A, Bert M, Chiotis A. Polym Degrad Stab 1982;5:245

$\underline{23}$ McNeill IC, Zulfiqar M, Kousar T. Polym Degrad Stab 1990;28:131.

24 Suzuki M, Wilkie CA. Polym Degrad Stab 1995;47:217.

25 Xue TJ, Wilkie CA. Polym Degrad Stab 1997;56:109.

$\underline{26}$ McNeill IC, Stevenson WTK. Polym Degrad Stab 1985; 10:247.

27 McNeill IC, Stevenson WTK. Polym Degrad Stab 1985; 10:319. 